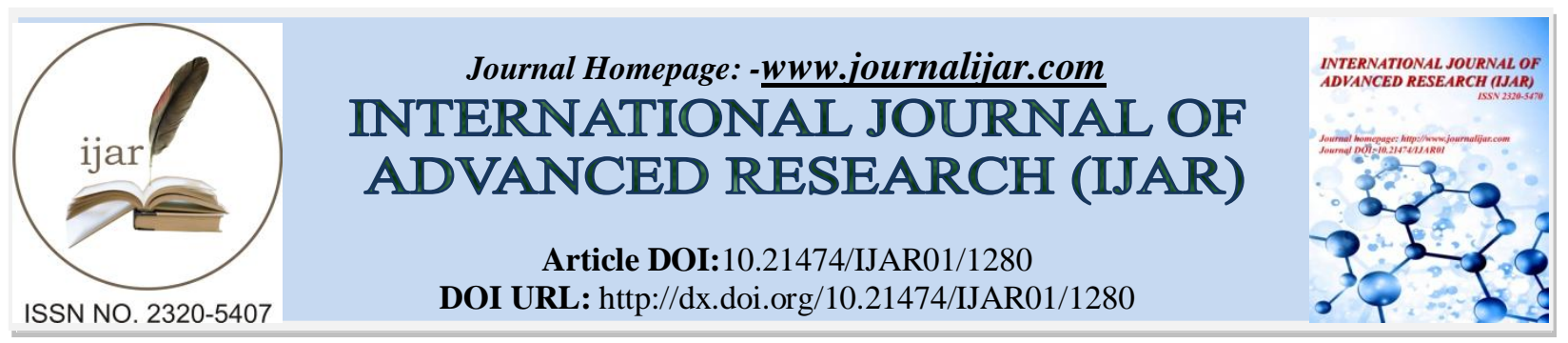

RESEARCH ARTICLE

\title{
AN OVERVIEW OF PEDIATRIC INGUINAL HERNIAS: EXPERIENCE AT A TERTIARY CARE CENTER IN NORTHERN PROVINCE OF SAUDI ARABIA.
}

\section{Umme Salma ${ }^{1}$, Nagah Mohamed Aboel-Fetoh ${ }^{2}$, Yasir Mehmood ${ }^{3}$, Modhi A. Alanizi ${ }^{4}$ and Omar Tabaan Alenezi ${ }^{5}$.}

1. Assistant Professor of Surgery, Northern Borders University, Arar, KSA.

2. Associate Professor of Public Health and Community Medicine, Faculty of Medicine, Sohag University, Egypt \& Faculty of Medicine, Northern Border University, KSA.

3. Assistant Professor of Surgery, Northern Borders University, Arar, KSA.

4. Intern, Faculty of Medicine, Northern border University, KSA.

5. Final year student, Faculty of Medicine, Northern border University, KSA.

\section{Manuscript Info}

Manuscript History

Received: 12 June 2016

Final Accepted: 19 July 2016

Published: August 2016

Key words:

Pediatric; Inguinal; Hernias; Herniotomy; Northern; Saudi Arabia.

\section{Abstract}

Background:Inguinal hernia repair is one of the most common pediatric operations performed nowadays. Majority are right sided indirect hernias and common in male gender. ${ }^{1,2}$ Presentation varies from asymptomatic to life threatening complications. Operations are usually done under general anesthesia in an elective setting but the acute presentations like obstruction or strangulation are managed in emergency.

Objectives:To see the clinical presentation and management outcome of congenital inguinal hernia cases who presented in the Pediatric Surgery Department of Qurrayatcentral hospital, Northern province, Kingdom of Saudi Arabia.

Subjects and Methods: 4 years descriptive study of pediatric patients with inguinal hernia in Central hospital of Qurrayat city, Kingdom of Saudi Arabia, excluding patients with comorbidities or congenital malformations. Data included age, gender, clinical presentation, involvement (unilateral or bilateral), content of the sac, associated conditions, operative choice (elective or emergency) and complications after operation. Data analysis was done using statistical package SPSS version 16.

Results: In 4 years, 520 patients (Male to female ratio 7:1) presented with inguinal hernia, majority less than 1 year (55\%) with right sided predominance $(56.5 \%)$. Undescended testis in $12(2.4 \%)$ and hydrocele in $9(1.8 \%)$ were the associated conditions. Some cases presented with contents like large intestine $(5.2 \%)$, appendix $(0.8 \%)$, testis $(0.6 \%)$ and small intestine or ovary $(0.4 \%)$ while $11.3 \%$ came in emergency as strangulated hernias. After operation, nearly all cases $(98.5 \%)$ passed without complications, recurrence occurred in $6(1.2 \%)$ cases and $2(0.4 \%)$ cases were complicated by wound infection, seen in older aged patients. Sac containing large intestine or appendix presented with complications.
Corresponding Author:Nagah Mohamed Aboel-Fetoh.

Address:Associate Professor of Public Health and Community Medicine, Faculty of Medicine, Northern Border Universitv. KSA. 
Conclusion: In this study the trend of presentation was more in children less than a year in age, with male predominance, and in most cases right side was involved, complications were less frequent but

seen in older children, in emergency cases and when the sac contents were large intestine or appendix.

Copy Right, IJAR, 2016,. All rights reserved.

\section{Introduction:-}

Inguinal hernia repair is one of the most common pediatric operations performed nowadays. Most inguinal hernias that are present at birth or in childhood are indirect inguinal hernias. Other less common types of ventral hernias include umbilical, epigastric, and incisional hernias. Its international incidence ranges from 1-5\% with $60 \%$ occurring on the right side. ${ }^{1,2}$

Its more prevalent in male gender and premature infants are the at risk population. Presentation varies from asymptomatic to life threatening complications. Strangulation depends on the contents of the sac as it may contain small or large intestinal loop, appendix, meckels or simple omentum. In female patients, fallopian tubes, ovaries or even uterus were also find in some studies as in a study in Nigeria by Osifo OD et al and in Netherlands by George EK et al. ${ }^{3,4}$

In a longitudinal cohort by Pan ML etal in Taiwan, the different aspects of pediatric hernias were studied, in which out of 92,308 studied individuals, 3881 underwent hernia repairs, with an incidence of $4.20 \%$ in children less than 7years. The boy/girl ratio was 4.27:1 and the unilateral/bilateral ratio was 3.77:1. The incidence of hernia repair among boys was highest during the first year of life, but then decreased with age. ${ }^{5}$

Operations are usually done under general anesthesia in an elective setting but the acute presentations are managed in emergency. Nowadays laparoscopic procedures are also performed for it with new advancements even in the emergency settings. The most important aspect of the management of neonatal inguinal hernias relate to its risk on incarceration, and emphasis is placed on this point. ${ }^{6,7,8}$ In study by Zamakhshary $\mathrm{M}$ etal done in Toronto, risk of incarceration in pediatric population waiting for hernia repair was studied and early operations were found to be more safe than the waiting population. ${ }^{9}$

This article covers the demographic profile, clinical presentation, different modes of treatment of groin hernias and their associated conditions like hydroceles or undescended testis etc and complication rates in the specific patient population.

\section{Objectives:}

To see the clinical presentation and management outcome of congenital inguinal hernia cases who presented in the Pediatric Surgery Department of Qurrayatcentral hospital, Northern province, Kingdom of Saudi Arabia.

\section{Materials and Methods:-}

This was a descriptive hospital based study including pediatric patients with inguinal hernia attending the Pediatric Surgery Department of the Central hospital of Qurayat city, Kingdom of Saudi Arabia, from January 2010 to December 2014. All cases of congenital inguinal hernia who presented in the Pediatric Surgery Department were included in this study excluding those having comorbidities or congenital malformations or secondary hernias. Data including age, gender, clinical presentation, involvement (unilateral or bilateral), content of the sac, associated conditions, condition of the operation (elective or emergency) and complications after operation were noted. The study analyzed collected data of 520 children submitted to inguinal hernia repair, under local/ regional anesthesia.

Ethical considerations:Permission to conduct the study was obtained from the Research and Ethics Committee at the College of Medicine, Northern Border University, Arar, Saudi Arabia. Data collectors gave a brief introduction to 
the mothers or fathers of the participating children by explaining the aims and significance of the study andinformed consent was obtained from them. No names were recorded on the questionnaires. Adequate training of data collectors took place to ensure protection of confidentiality, and all questionnaires were kept safe.

Statistical Analysis:Collected data were coded and analyzed using statistical package for the social sciences (SPSS, version 15).The w2-test was used as a test of significance, and differences were considered significant at $P$ value 0.05 or less.

\section{Results \& Discussion:-}

About half (46.3\%) of cases presented at 3 months to one year of age, about third (33.8\%) of them presented at 1-6 years and only $11 \%$ were presented at the age of more than 6 year. $87.7 \%$ of cases were males and only $12.3 \%$ were females with a ratio of 7:1. (Table -1)

Table 1: Age groups and sex of studied congenital hernia cases ofQurrayat,Northern area, KSA, 1436.

\begin{tabular}{|c|c|c|}
\hline Age & No. & $\%$ \\
\hline $3 \mathrm{~m}-$ & 46 & 8.8 \\
\hline 1 year - & 241 & 46.3 \\
\hline 6 years - & 176 & 33.8 \\
\hline$>6 y s$ & 57 & 11.0 \\
\hline Total & 520 & 100.0 \\
\hline \multicolumn{3}{|l|}{ Sex } \\
\hline Female & 64 & 12.3 \\
\hline Male & 456 & 87.7 \\
\hline Total & 520 & 100.0 \\
\hline
\end{tabular}

Right sided hernia is the commonest type (56.5\%) followed by the left sided (34.8\%) and only $8.7 \%$ were bilateral hernia. (Table -2)

Table 2:Side of herniaof studied congenital hernia cases of Qurrayat, Northern area, KSA, 1436-1437.

\begin{tabular}{|c|c|c|}
\hline Side of hernia & No. & \% \\
\hline Bilateral & 45 & 8.7 \\
\hline Left & 181 & 34.8 \\
\hline Right & 294 & 56.5 \\
\hline
\end{tabular}

There were no associated conditions in $95.0 \%$ of cases, un-descended testis in $12(2.4 \%)$ and hydrocele in $9(1.8 \%)$. (Table -3).

Table 3:Content of the sacof studied congenital hernia cases ofQurrayat, Northern area, KSA, 1436-1437.

\begin{tabular}{|c|c|c|}
\hline Content of the sac & No. & \% \\
\hline Spontaneously reduced & 484 & 93.1 \\
\hline Loop of large intestine & 27 & 5.2 \\
\hline Appendix & 4 & .8 \\
\hline Right or left testis & 3 & .6 \\
\hline Loop of small intestine or ovary & 2 & .4 \\
\hline
\end{tabular}

Contents of the sac were spontaneously reduced in almost all of cases (93.1\%), Loop of large intestine was in 5.2\%, appendix in 4(0.8\%), testis in 3(0.6) and Loop of small intestine or ovary in 2(0.4\%) of cases. (Table -4).

Table4:Associated conditionsof studied congenital hernia cases of Qurrayat,Northern area, KSA, 1436-1437.

\begin{tabular}{|c|c|c|}
\hline Associated conditions & No. & \% \\
\hline No associated conditions & 494 & 95.0 \\
\hline Un-descended -testis & 12 & 2.4 \\
\hline Hydrocele & 9 & 1.8 \\
\hline Others & 11 & 2.2 \\
\hline
\end{tabular}

$88.7 \%$ of cases operated electively and only $11.3 \%$ come in emergency. Regarding the type of operation, combined herniotomy and herniography was the surgical intervention in (98.5\%).(Table -5)

Table 5:Types of operationof studied congenital hernia cases of Qurrayat,Northern area, KSA, 1436-1437. 


\begin{tabular}{|c|c|c|}
\hline Types of operation & No & $\%$ \\
\hline Combined herniotomy\&herniorophy & 514 & 98.8 \\
\hline Herniotomy\& appendectomy & 3 & 0.6 \\
\hline Herniotomy\& orchiectomy & 2 & 0.4 \\
\hline Herniotomy\& hydrocele & 1 & 0.2 \\
\hline
\end{tabular}

After operation, nearly all cases $(98.5 \%)$ passed without complications, recurrence occurs in $6(1.2 \%)$ cases and $2(0.4 \%)$ cases were complicated by wound infection. (Table -6$)$

Table 6:-Complication after operationof studied congenital hernia cases of Qurrayat, Northern area, KSA, 14361437.

\begin{tabular}{|c|c|c|}
\hline Complication after operation & No & $\%$ \\
\hline Nocomplications & 512 & 98.5 \\
\hline Wound infection & 2 & .4 \\
\hline Recurrence & 6 & 1.2 \\
\hline
\end{tabular}

Inguinal hernia surgeries are a frequently common procedure done by the pediatric surgeons. The procedure can be difficult even in the most experienced hands and especially when performed as an emergency. ${ }^{1}$ The results from this survey show that age at presentation, sex and presenting side are similar to those reported in several large American series and usually the presentation is a right sided involvement as was evident in this study (56\%) and is justified in other studies of this patient population like by Pan ML etal and Manoharan et al. ${ }^{5,8} \mathrm{~A}$ trend is seen of a unilateral to bilateral ratio of 10:1, which was slightly more than majority of the series like by Pan ML et al this ratio was about $3.7: 1 .^{5}$

Majority of the patient who underwent this operation were infants $(55 \%)$ below the age of one year. The same pattern was seen in various other studies like by Aboagye $\mathrm{J}$ et al, ${ }^{10}$ and it was seen that they were more associated with complicated presentations if not treated in earlier life.

In different studies the associated conditions were the congenital problems like connective tissue disorders, increased intraabdominal pressure, abdominal wall defects or family history of congenital hernias, but in this study such patients were excluded and the only associated conditions were congenital hydrocoeles and undescended testis. ${ }^{11,12,13}$

Regarding the mode of surgery about $11 \%$ underwent emergency surgery due to acute presentations like strangulation or incarceration while $89 \%$ underwent elective groin surgeries. ${ }^{9,14}$ As contents of the sac during the surgery were identified, majority of the patients had a spontaneously reduced sac while in only $7 \%$ the sac contents were small or large intestinal loop, testis or appendix. In a total of 64 female patients only 2 were presented with ovary as a content of sac, while in large series of similar such studies ovaries, fallopian tubes and even uterus were found as content of the sac. ${ }^{3,4,15,16,17}$

Although less common but the noticeable postoperative complaints were wound infection and recurrence of hernias. In the cases of sacs containing loop of large intestine, 24(88.9\%) of them passed without complications while $3(11.1 \%)$ showed recurrence of the hernia. Out of all only two cases underwent postoperative wound infection. It was found in older children, both cases in more than 6 years age group and the content of the sac was an inflamed appendix. In various similar studies it was seen that these complications were more in the patients who were operated as an acute emergency, while the elective cases were usually without any complication

Although all of these cases were operated as an open procedure in our setup but the recent advances in the laparoscopic surgery are making it a favorable procedure for elective as well as selected emergency cases especially after manual reduction of the incarcerated hernias. ${ }^{18,19,20}$ It is also helpful in evaluating the contralateral side as majority of the patients present with an occult hernia of the other side also. ${ }^{21,22,23,24}$

\section{Conclusion:-}

Pediatric Inguinal hernia repair is a routine surgical procedure. This study has helped in giving an overview of the presentation of pediatric hernias in. To conclude, in the study the trend of presentation was more in children less 
than a year in age, with male predominance, and in most cases right side was involved, complications were less frequent but seen in late presentations and in emergency cases. Although there is a lot of advancements in the last 2 decades still numerous issues, including the need to explore the contralateral groin, use of laparoscopy and anesthetic approach, remain unsettled.

\section{Acknowledgement:-}

We are grateful to Prof. Dr. IqtidarTaufiq for reviewing the paper and toDuaa M. Al-sharari, Alaa O. Alibrahim, Abdalla Mohamed Bakr Ali and Walaa Muhammad Bakar Ali for their help in different steps of the research.

\section{References:-}

1. Wang KS, Committee on Fetus and Newborn, American Academy of Pediatrics, Section on Surgery, American Academy of Pediatrics. Assessment and management of inguinal hernia in infants. Pediatrics 2012; 130:768.

2. Antonoff MB, Kreykes NS, Saltzman DA, Acton RD. American Academy of Pediatrics Section on Surgery hernia survey revisited. J PediatrSurg 2005; 40:1009.

3. Osifo OD, Ovueni ME. Inguinal hernia in Nigerian female children: beware of ovary and fallopian tube as contents. Hernia 2009; 13:149.

4. George EK, Oudesluys-Murphy AM, Madern GC, et al. Inguinal hernias containing the uterus, fallopian tube, and ovary in premature female infants. J Pediatr 2000; 136:696.

5. Pan ML, Chang WP, Lee HC, et al. A longitudinal cohort study of incidence rates of inguinal hernia repair in 0to 6-year-old children. J PediatrSurg 2013; 48:2327.

6. Aiken JJ. Inguinal hernias. In: Nelson Textbook of Pediatrics, 17th, Behman RE, Kliegman RM, Jenson HB. (Eds), Saunders, Philadelphia 2004. p.1293.

7. Paidas C, Kayton ML. Inguinal hernia. In: Oski's Pediatrics: Principles and Practice, 4th, McMillan JA, DeAngelis CD, Feigin RD, et al. (Eds), Lippincott Williams \& Wilkins, Philadelphia 2006. p.1925.

8. Manoharan S, Samarakkody U, Kulkarni M, et al. Evidence-based change of practice in the management of unilateral inguinal hernia. J PediatrSurg 2005; 40:1163.

9. Zamakhshary M, To T, Guan J, Langer JC. Risk of incarceration of inguinal hernia among infants and young children awaiting elective surgery. CMAJ 2008; 179:1001.

10. Aboagye J, Goldstein SD, Salazar JH, et al. Age at presentation of common pediatric surgical conditions: Reexamining dogma. J PediatrSurg 2014; 49:995.

11. Chen YC, Wu JC, Liu L, et al. Correlation between ventriculoperitoneal shunts and inguinal hernias in children: an 8-year follow-up. Pediatrics 2011; 128:e121.

12. Sarpel U, Palmer SK, Dolgin SE. The incidence of complete androgen insensitivity in girls with inguinal hernias and assessment of screening by vaginal length measurement. J PediatrSurg 2005; 40:133.

13. Katz DA. Evaluation and management of inguinal and umbilical hernias. Pediatr Ann 2001; 30:729.

14. Kaya M, Hückstedt T, Schier F. Laparoscopic approach to incarcerated inguinal hernia in children. J PediatrSurg 2006; 41:567.

15. Boley SJ, Cahn D, Lauer T, et al. The irreducible ovary: a true emergency. J PediatrSurg 1991; 26:1035.

16. Jedrzejewski G, Stankiewicz A, Wieczorek AP. Uterus and ovary hernia of the canal of Nuck. PediatrRadiol 2008; 38:1257.

17. Merriman TE, Auldist AW. Ovarian torsion in inguinal hernias. PediatrSurgInt 2000; 16:383.

18. Spurbeck WW, Prasad R, Lobe TE. Two-year experience with minimally invasive herniorrhaphy in children. SurgEndosc 2005; 19:551.

19. Schier F. Laparoscopic inguinal hernia repair-a prospective personal series of 542 children. J PediatrSurg 2006; 41:1081.

20. Schier F, Montupet P, Esposito C. Laparoscopic inguinal herniorrhaphy in children: a three-center experience with 933 repairs. J PediatrSurg 2002; 37:395.

21. Maillet OP, Garnier S, Dadure C, et al. Inguinal hernia in premature boys: should we systematically explore the contralateral side? J PediatrSurg 2014; 49:1419.

22. Klin B, Efrati Y, Abu-Kishk I, et al. The contribution of intraoperative transinguinal laparoscopic examination of the contralateral side to the repair of inguinal hernias in children. World J Pediatr 2010; 6:119.

23. Alzahem A. Laparoscopic versus open inguinal herniotomy in infants and children: a meta-analysis. PediatrSurgInt 2011; 27:605.

24. Shalaby R, Ismail M, Dorgham A, et al. Laparoscopic hernia repair in infancy and childhood: evaluation of 2 different techniques. J PediatrSurg 2010; 45:2210. 